\title{
CINÉTICA DE DEGRADAÇÃo DA COR DE PÓLEN APÍCOLA DURANTE A SECAGEM INFRAVERMELHO
}

\author{
L. D. M. S. BOREL ${ }^{*}$, M. C. LINHARES, M. M. PRADO \\ Universidade Federal de Sergipe, Departamento de Engenharia Química \\ e-mail: dahiane.ms@hotmail.com
}

\begin{abstract}
RESUMO
O pólen apícola atrai interesse devido à alta disponibilidade de compostos bioativos em sua composição. Para conservação de seus atributos de qualidade, o pólen deve ser submetido à secagem. As condições do processo podem, no entanto, causar a degradação de compostos de interesse, o que pode ser evidenciado por alterações colorimétricas do material. Logo, o objetivo deste trabalho foi estudar a mudança de cor dos grãos de pólen submetidos à secagem infravermelho (IV) em camada fina e avaliar o efeito da intensidade de radiação IV sobre tais mudanças. A cor do pólen foi mensurada através das coordenadas cromáticas $L^{*}, a^{*}$ e $b^{*}$ dos grãos in natura e ao longo da secagem IV com intensidades de radiação IV de 100,400 e $700 \mathrm{~W} / \mathrm{m}^{2}$. De posse desses parâmetros, calculou-se o índice de escurecimento (IE) dos grãos e a descrição cinética do escurecimento foi investigada ajustando-se equações de ordem zero e de primeira ordem. $\mathrm{O}$ aumento da intensidade de radiação provocou, como esperado, maior remoção de umidade em menor tempo de processo. Para a condição de $100 \mathrm{~W} / \mathrm{m}^{2}$, a cinética de escurecimento foi melhor descrita por uma equação de ordem zero, para as outras condições a equação de $1^{\mathrm{a}}$ ordem foi mais adequada. A degradação da cor dos grãos foi intensificada pelo aumento da intensidade de radiação indicando que as altas temperaturas atingidas pela amostra durante a secagem IV podem ter favorecido a ocorrência das reações de escurecimento.
\end{abstract}

\section{INTRODUÇÃO}

O pólen apícola é resultado dos grãos de pólen coletados pelas abelhas das flores aglutinados com néctar e sua saliva.

Trata-se de um material rico em muitos compostos bioativos com alto valor agregado. Além de suplemento alimentar, sua utilização é associada a efeitos antimicrobiano, antifúngico, antioxidante, anti-radiação, hepatoprotetor, quimiopreventivo e antiinflamatório no auxílio ao tratamento e prevenção de diversas doenças (PASCOAL et al., 2014).
Devido ao elevado teor de açúcares e à alta higroscopicidade, o pólen constitui um rico substrato para o desenvolvimento microbiano. Além disso, fungos e bactérias presentes no intestino das abelhas e nos apiários afetam qualidade microbiológica do pólen (FERREIRA, 2012). Portanto, não é recomendado o consumo do pólen in natura, visto que pode afetar a saúde do consumidor.

A secagem do pólen apícola coletado é indispensável para evitar a ocorrência de fermentações indesejáveis. Segundo a legislação brasileira, o material coletado in natura com 20 a $30 \%$ b.u. de umidade deve 
ter esse teor reduzido a $4 \%$ b.u. através de um processo de secagem (BRASIL, 2001).

A aplicação de energia eletromagnética na região do infravermelho (com comprimentos de onda entre 0,75 e $1000 \mu \mathrm{m}$ ) vem sendo amplamente investigada para promover a secagem de diferentes materiais de modo rápido e eficiente (JUN et al., 2010).

Dentre as principais vantagens da secagem infravermelho estão: (a) a simplicidade do equipamento requerido; (b) a fácil incorporação do aquecimento IV com outros métodos de aquecimento (convectivo, condutivo e microondas); (c) o fácil direcionamento da fonte de calor e transferência da energia eletromagnética na região do infravermelho para a superfície do material sem aquecimento do ar; (d) a obtenção de altas taxas de transferência de calor com aquecedores compactos; (e) a alta qualidade do produto final e, (f) o menor tempo de processamento e a significativa economia de energia (BARBOSA NETO et al., 2014).

As vantagens supracitadas comparadas ao que os secadores convencionais podem oferecer fazem da secagem IV uma excelente alternativa a ser adotada por apicultores a fim de obter pólen apícola desidratado com alta qualidade e a baixos custos. O pólen apícola parece ser muito atrativo para a secagem IV, à medida que contém altos teores de umidade, proteínas e lipídeos, os quais possuem boa capacidade de absorção de energia IV (SANDU, 1986). Devido ao pequeno tamanho dos grãos de pólen, a penetração dos raios IV tende a ser muito boa, o que pode contribuir para um aquecimento uniforme, bem como para superar a harmomegatia, que é a habilidade da estrutura do pólen de reter a umidade em seu interior (KATIFORI et al., 2010). As altas taxas de secagem podem também prevenir a oxidação e a perda de substâncias termosensíveis durante $\mathrm{O}$ processo. Ademais, o uso de aquecimento IV permite realizar simultaneamente a secagem e a desinfestação do pólen apícola.

Entretanto, a secagem IV pode resultar em produtos de baixa qualidade. Condições operacionais escolhidas inadequadamente, tais como altas intensidades de radiação IV e longo tempo de exposição a essa energia eletromagnética pode causar superaquecimento e danos ao material. Logo, as vantagens técnicas e econômicas da intensificação do processo ao aplicar a radiação IV devem ser acompanhadas pela qualidade do produto. É importante não somente controlar a intensidade de radiação, mas também continuamente monitorar a temperatura e alguns atributos de qualidade do produto.

Cor e teor de umidade são dois dos mais importantes parâmetros de qualidade do pólen desidratado. A presença de pigmentos, flavonóides ou carotenóides, determina a cor do grão de pólen. O pólen apícola é um material granular constituído por partículas de diferentes cores (amarelo, verde, laranja, castanho) em função da diversidade das espécies florais visitadas pelas abelhas (ROCHA, 2013).

Alterações na cor dos grãos durante a secagem estão associadas principalmente ao escurecimento não enzimático, à medida que o pólen é rico em açúcares, aminoácidos e carotenoides. Três importantes causas podem estar envolvidas no desenvolvimento do escurecimento não enzimático: caramelização de açúcares, reação de Maillard e oxidação de vitaminas (MANZOCCO et al., 2000).

A intensidade das reações de escurecimento não enzimático é função do teor e da natureza do carboidrato presente no material. Em alguns casos, isso torna o alimento mais atrativo através da intensificação do flavor, por exemplo, na produção do chocolate. Entretanto, no tocante ao pólen apícola desidratado, o produto submetido a elevadas temperaturas é comumente caracterizado por coloração mais 
escura e pelo gosto amargo. Além de influenciar a percepção do consumidor, mudanças na cor dos grãos podem evidenciar degradação de compostos bioativos importantes (LAVERDE et al., 2011).

Logo, as medidas de cor são essenciais para avaliar a preservação da qualidade físicoquímica dos grãos de pólen durante o seu processamento.

A degradação da cor do material durante o processo de secagem pode ser avaliada com base no índice de escurecimento (IE), calculado a partir das coordenadas $L^{*}, a^{*}$ e $b^{*}$ do sistema Hunter (PONKHAM et al., 2012). Este índice mede a magnitude da cor castanha no material e é um parâmetro que indica a ocorrência do escurecimento enzimático ou não enzimático, pois estes conduzem à formação de pigmentos de cor marrom ou negra no material.

$\mathrm{O}$ impacto do aquecimento $\mathrm{e}$ armazenamento de alimentos sobre o escurecimento do produto tem sido bastante investigado (ACEVEDO et al., 2006). Estudos abordam o efeito da fonte (convectiva ou radiante) e da taxa de aquecimento sobre o escurecimento ocorrido durante o processamento térmico de alimentos. De modo geral, relata-se que a técnica empregada não influencia diretamente as alterações colorimétricas, mas sim os gradientes de temperatura, o tempo de processamento e a taxa de aquecimento impostas ao material (MATSUDA et al., 2013).

Matsuda et al. (2013) ressaltam a importância de conhecer o comportamento cinético do escurecimento do material frente ao processamento térmico visto que a taxa de reação e taxa de aquecimento estão relacionadas. Assim, a equação cinética que descreve o processo pode ajudar no controle e garantir a melhoria da qualidade do produto obtido. Equações de ordem zero e de primeira ordem têm sido comumente aplicadas para descrever o escurecimento de diferentes materiais.

Apesar dos vários trabalhos sobre a cinética de degradação da cor de diferentes produtos agrícolas, não foram encontradas na literatura estudos acerca das alterações colorimétricas de pólen apícola durante a secagem infravermelho.

Diante deste contexto, o objetivo deste trabalho foi estudar as alterações colorimétricas em grãos de pólen submetidos à secagem infravermelho e avaliar o efeito da intensidade de radiação IV sobre a cinética de escurecimento do material.

\section{MATERIAIS E MÉTODOS}

\subsection{Materiais}

Os grãos de pólen apícola utilizados neste trabalho foram coletados de apiários situados na Associação dos Concessionários do Distrito de Irrigação do Platô de Neópolis (entre $10^{\circ} 17^{\prime}$ e $10^{\circ} 24^{\prime} \mathrm{S}$; entre $36^{\circ} 36^{\prime}$ e $35^{\circ}$ $\left.45^{\prime} \mathrm{W}\right)$. Trata-se de um pólen cuja origem botânica é, predominantemente, de coqueiro (Cocos nucifera L.). A umidade inicial do pólen apícola recebido in natura ficou na faixa de 0,21 a 0,30 b.u.. Para assegurar a disponibilidade do material para os experimentos, após a classificação granulométrica, o material foi acondicionado em recipientes de alumínio, para cada fração granulométrica, em freezer doméstico a $5^{\circ} \mathrm{C}$. A amostra do material adquirido é mostrada na Figura 1.

Figura 1 - Amostra de pólen apícola obtida em apiário situado no Platô de Neópolis - SE

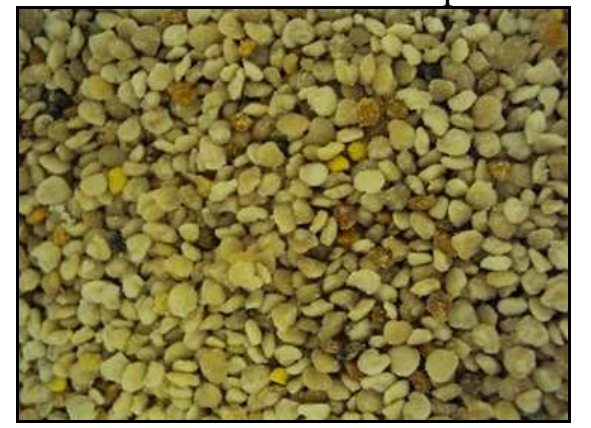




\subsection{Aparato experimental}

O aparato experimental utilizado está ilustrado na Figura 2. Empregou-se uma fonte de radiação infravermelho (IV) constituída por uma lâmpada incandescente de $250 \mathrm{~W}$ (marca Ourolux, E27) acoplada a uma câmara de secagem construída em madeira, revestida internamente de material isolante a fim de executar-se a secagem IV em camada fina.

Figura 2 - Aparato experimental.

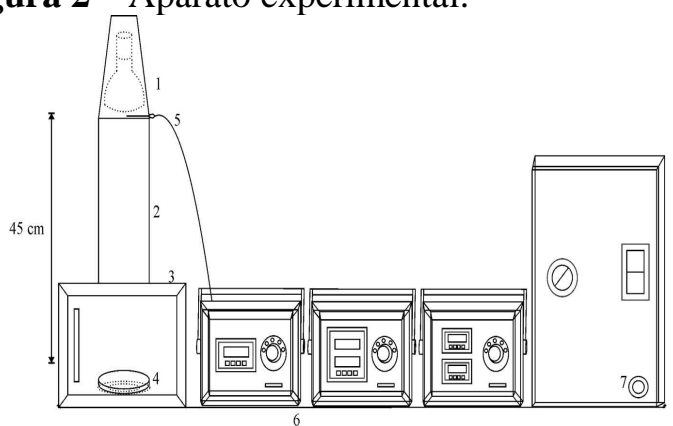

(1) Fonte de aquecimento IV (2) Suporte de material isolante e refletivo (3) Câmara de secagem (4) Bandeja de alumínio (5) Termopar (6) Indicador de temperatura (7) Regulador de voltagem.

A distância entre a fonte de aquecimento infravermelho e a superfície da amostra disposta em monocamada foi fixada em 45 centímetros.

A potência da lâmpada foi regulada por meio de um variac de modo a aplicar a intensidades de radiação (IR) de 100, 400 e $700 \mathrm{~W} / \mathrm{m}^{2}$.

\subsection{Metodologia experimental}

\subsubsection{Experimentos de Secagem}

Inicialmente, a fonte de aquecimento IV foi ligada e a intensidade regulada.

Então, esperou-se a estabilização do sistema de aquecimento. Após a estabilização da temperatura, uma bandeja de alumínio, contendo a amostra de $15 \mathrm{~g}$ de pólen apícola, disposta em monocamada, foi colocada na câmara de secagem e exposta à radiação IV.
A temperatura da fonte de aquecimento infravermelho foi monitorada ao longo dos experimentos por meio de um termopar. Os valores médios de temperatura da fonte correspondentes às intensidades de fluxo de energia radiante aplicadas foram 102,4; 141,6 e $180,6^{\circ} \mathrm{C}$.

Para a determinação da cinética de secagem do material, foram feitas pesagens da amostra de grãos em intervalos de tempo prédeterminados, obtendo-se a massa de água evaporada por diferença das pesagens efetuadas. A temperatura da superfície dos grãos foi também medida ao longo do processo com o auxílio de um pirômetro óptico digital (Impac, modelo IP850, precisão $0,1^{\circ} \mathrm{C}$ ). Ao final de cada experimento, a massa de sólido seco foi determinada pelo método direto da estufa, com temperatura de $(60 \pm$ $3,0)^{\circ} \mathrm{C}$ até massa constante.

2.2.2 Avaliação dos atributos de qualidade dos grãos de pólen

A cor dos grãos de pólen foi mensurada com auxilio de um colorímetro portátil (MiniScan Ez, marca Hunterlab) com fonte de luz D65, ângulo de observação de $10^{\circ} \mathrm{e}$ abertura da célula de medida de $30 \mathrm{~mm}$, efetuando-se as medidas das coordenadas cromáticas $L^{*}, a^{*}, b^{*}$ do sistema CIELab nos grãos do material in natura e ao longo do processo de secagem.

A calibração do colorímetro foi realizada com as placas, branca e preta, padrão, seguindo as instruções do fabricante.

De posse dos valores das coordenadas cromáticas foram determinados parâmetros de alteração de coloração. A diferença total dos parâmetros de cor $\left(\Delta \mathrm{E}^{*}\right)$ do material seco foi determinada de acordo com a Equação (1) (PALOU et al., 1999):

$$
\Delta E^{*}=\left[\left(\Delta L^{*}\right)^{2}+\left(\Delta a^{*}\right)^{2}+\left(\Delta b^{*}\right)^{2}\right]^{1 / 2}
$$

Sendo: 
$\Delta L^{*}=L^{*}-L_{o}^{*}$

$\Delta a^{*}=a^{*}-a^{*}$ 。

$\Delta b^{*}=b^{*}-b^{*}{ }_{o}$

em que $L^{*}$ é a luminosidade do material, de 0 (preto) a 100 (branco); $a^{*}$ indica a cor do verde ao vermelho e $b^{*}$ indica a cor do azul ao amarelo. Os parâmetros $a^{*}$ e $b^{*}$ variam entre -60 a +60 . O subscrito "o" indica o valor determinado da leitura da cor do material in natura.

A partir das coordenadas retangulares do sistema CIELab, foram determinadas as coordenadas cilíndricas, croma $\left(C^{*}\right)$ e hue $\left(H^{*}\right)$ de acordo com as Equações (5) e (6), respectivamente.

$$
\begin{aligned}
& C^{*}=\sqrt{\left(a^{*}\right)^{2}+\left(b^{*}\right)^{2}} \\
& H^{*}=\operatorname{tg}^{-1} \frac{b^{*}}{a^{*}}
\end{aligned}
$$

O índice de escurecimento (IE) dos grãos ao longo do processo de secagem foi determinado de acordo com a Equação (7) (PALOU et al., 1999):

$$
I E=\frac{100(x-0,031)}{0,17}
$$

Sendo:

$$
x=\frac{a^{*}+1,75 L^{*}}{5,645 L^{*}+a^{*}-3,012 b^{*}}
$$

A descrição da cinética do escurecimento das partículas foi investigada ajustando-se equações cinéticas de ordem zero e de primeira ordem aos dados experimentais conforme as Equações (9) e (10), respectivamente.

$$
\begin{aligned}
& I E=C_{o}+\alpha_{0} \cdot t \\
& \frac{I E}{I E_{o}}=\exp \left(\alpha_{1} \cdot t\right)
\end{aligned}
$$

em que IE é o valor do índice de escurecimento em determinado tempo, $I E_{o}$ é o valor do índice de escurecimento do material in natura e $C_{o}$ e $\alpha_{0}$ são as constantes da equação cinética de ordem zero e $\alpha_{1}$ é a constante cinética de primeira ordem.

A dependência da constante cinética de escurecimento de $1^{\text {a }}$ ordem em relação à temperatura foi investigada considerando uma função do tipo Arrhenius conforme Equação (11):

$$
\alpha_{1}=\alpha \exp \left(\frac{-E_{a}}{R T}\right)
$$

sendo $\alpha$ um fator pré-exponencial $\left(\mathrm{min}^{-1}\right), E_{a}$ a energia de ativação $\left(\mathrm{kJ} \mathrm{mol}^{-1}\right), \mathrm{R}$ a constante universal dos gases $\left(8,314 \mathrm{~J} \mathrm{~mol}^{-1} \mathrm{~K}^{-1}\right)$ e $T$ a temperatura absoluta da superfície do grão.

\section{RESULTADOS E DISCUSSÕES}

O comportamento típico da cinética de secagem IV do pólen apícola, em termos do adimensional de umidade e da temperatura do material ao longo do tempo, para as diferentes intensidades de radiação empregadas são apresentadas nas Figura 3 e 4, respectivamente.

Figura 3 - Adimensional de umidade em função do tempo parametrizada nas diferentes intensidades de radiação empregadas

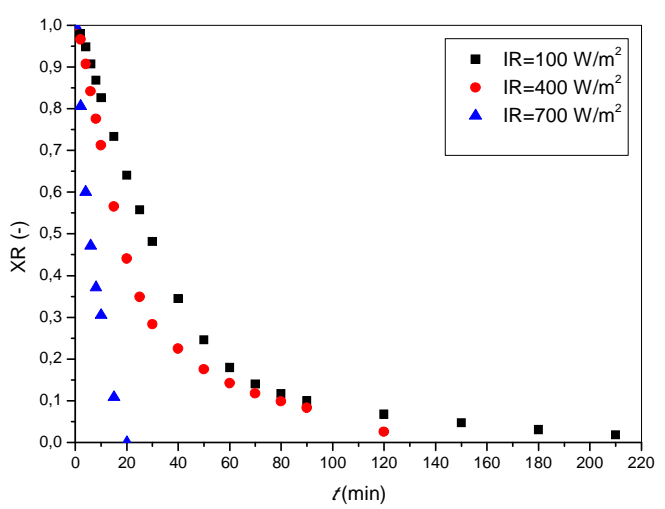


Figura 4 - Temperatura da superfície dos grãos de pólen em função do tempo de secagem, nas diferentes intensidades de radiação empregadas.

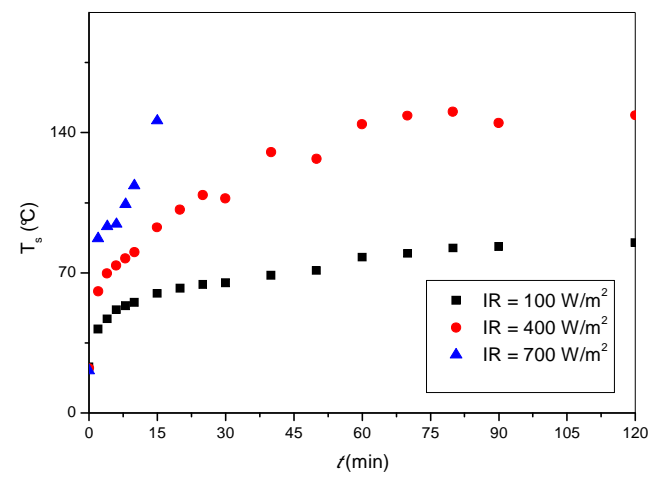

Como esperado, o aumento da intensidade de radiação provocou uma maior remoção de umidade, num menor tempo de processo. Com base nos dados apresentados na Figura 3, verifica-se uma redução de $90 \%$ da umidade contida na amostra com um tempo $76 \%$ menor, ao se aumentar a potência da fonte de 100 para $700 \mathrm{~W} / \mathrm{m}^{2}$. O tempo de secagem para reduzir o teor de umidade dos grãos para o valor alvo de $4 \%$ b.u., recomendado pela legislação brasileira, foi de $(60 \pm 5)$ min, $(18 \pm 2)$ min e $(9 \pm 1)$ min, para as intensidades de radiação IV de 100, 400 e $700 \mathrm{~W} / \mathrm{m}^{2}$, respectivamente.

Uma redução no tempo de secagem com o aumento na potência IV também foi reportada por Pawar et al. (2008). No entanto, no trabalho de Santos et al. (2010), a aplicação de elevadas intensidades de energia eletromagnética na região do IV provocou a impermeabilização da superfície de sementes de Moringa oleifera L, que atuou como resistência extra à transferência de massa e aumentou consideravelmente o tempo de secagem.

$\mathrm{O}$ aumento da intensidade de radiação IV levou a uma maior absorção dessa energia eletromagnética pelos componentes do material, causando uma maior vibração molecular e uma maior taxa de aquecimento (Figura 4). O significativo aumento da temperatura das partículas e, consequentemente, da pressão de vapor dentro delas, resultou em maiores taxas de secagem do pólen.

O pólen apícola é rico em carotenóides e flavonóides, pigmentos que conferem cor aos materiais biológicos em geral (amarelo, laranja, vermelho). A cor é um atributo de qualidade física de importância econômica, visto que influencia a atratividade do produto ao consumidor e constitui um parâmetro que pode indicar a degradação química do material processado.

As alterações colorimétricas sofridas pelo pólen durante o processo de secagem foram mensuradas através da leitura das coordenadas $L^{*}, a^{*}$ e $b^{*}$ do sistema Hunter, a partir dos quais foi possível calcular o índice colorimétrico diferença de cor $\left(\Delta E^{*}\right)$ que indica a variação da cor do produto com $8 \%$ b.u. de umidade em relação ao material in natura.

Os resultados obtidos são apresentados na Tabela 1 .

Tabela 1 - Parâmetros colorimétricos do pólen apícola in natura e desidratado com $8 \%$ de umidade b.u..

\begin{tabular}{c|c|c|c|c|c} 
& Leitura & $\boldsymbol{L}^{*}$ & $\boldsymbol{a}^{*}$ & $\boldsymbol{b}^{*}$ & $\boldsymbol{\Delta} \boldsymbol{E}^{*}$ \\
\hline $\mathrm{IR}=100$ & In natura & 61,90 & 5,18 & 28,19 & \multirow{2}{*}{1,19} \\
\cline { 2 - 5 } $\mathrm{W} / \mathrm{m}^{2}$ & Seco & 61,06 & 5,80 & 29,11 & \\
\hline $\mathrm{IR}=400$ & In natura & 62,94 & 5,48 & 28,64 & \multirow{2}{*}{7,26} \\
$\mathrm{~W} / \mathrm{m}^{2}$ & Seco & 55,96 & 6,52 & 30,35 & \\
\hline $\mathrm{N}=700$ & In natura & 61,21 & 6,27 & 29,24 & 23,1 \\
$\mathrm{~W} / \mathrm{m}^{2}$ & Seco & 38,55 & 10,54 & 26,83 & 8
\end{tabular}

Verificou-se que as mudanças colorimétricas foram intensificadas pelo aumento da intensidade de radiação.

Avaliando-se cada coordenada cromatográfica isoladamente durante a secagem IV em camada fina, o valor da luminosidade $\left(L^{*}\right)$ do pólen submetido à intensidade de radiação IV de $100 \mathrm{~W} / \mathrm{m}^{2}$ não foi significativamente diferente daquele do pólen in natura. Por sua vez, amostras expostas a maiores intensidades de radiação 
IV, 400 e $700 \mathrm{~W} / \mathrm{m}^{2}$, tiveram valores de $L^{*}$ menores quando comparado com o pólen in natura, o que evidencia o escurecimento do material durante o processo de secagem. Os grãos submetidos à intensidade de radiação IV de $700 \mathrm{~W} / \mathrm{m}^{2}$, por exemplo, tiveram o brilho reduzido em $37 \%$.

A perda de brilho de diversos materiais tem sido comumente reportada na secagem convectiva (ARGYROPOULOS e MULLER, 2014). Para a secagem de fatias de cenoura, Wu et al. (2014) verificaram que aplicação da radiação IV induziu uma maior luminosidade da superfície das amostras, melhorando sua refletividade, o que não foi observado no presente trabalho.

A coordenada $a^{*}$ apresentou tendência de aumento no sentido da coloração vermelha em todas as condições empregadas. Já o parâmetro $b^{*}$ sofreu decréscimo na condição de IR $=700 \mathrm{~W} / \mathrm{m}^{2}$ embora tenha apresentado tendência de aumento na direção do amarelo para as outras condições de IR. Estes resultados indicam uma tendência de aumento da tonalidade castanha dos grãos de pólen secos.

A alteração nos parâmetros colorimétricos durante a secagem, bem como o desenvolvimento de off-flavors, frequentemente indica a ocorrência de reações de escurecimento, enzimático ou não enzimático, no material.

Para avaliar o escurecimento do pólen apícola, utilizaram-se os valores das coordenadas colorimétricas no cálculo do índice de escurecimento. $O$ índice de escurecimento mede a pureza da cor castanha na amostra e por isso é um parâmetro que indica a formação dos pigmentos amarronzados decorrente das reações de escurecimento durante $\mathrm{o}$ processo de secagem.

As curvas de evolução do índice de escurecimento durante a secagem infravermelho dos grãos de pólen apícola para as diferentes intensidades de radiação empregadas são apresentadas na Figura 7.

Figura 7 - Índice de escurecimento dos grãos de pólen apícola ao longo do processo de secagem IV em camada fina, parametrizado nas diferentes intensidades de radiação IV empregadas

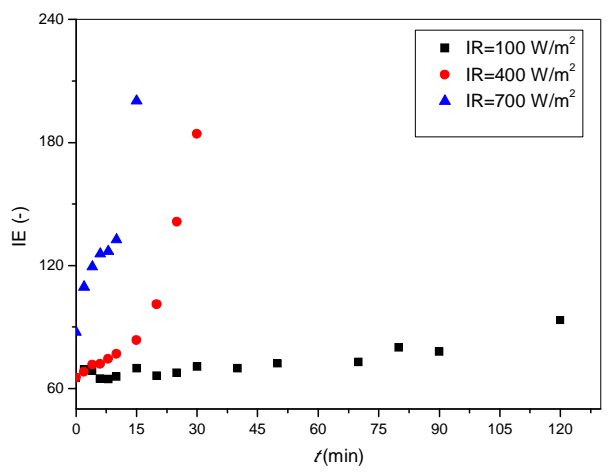

Conforme pode ser observado através da Figura 7, o escurecimento dos grãos foi intensificado pelo aumento da potência de radiação. Tal resultado pode indicar a ocorrência de reações de escurecimento, enzimático ou não enzimático, no material. Dentre as reações de escurecimento nãoenzimático, as reações de Maillard envolvem aminoácidos e açúcares redutores na produção melanoidinas, que são pigmentos de cor marrom. Visto que o pólen apícola possui, em sua composição, elevados teores de açúcar e aminoácidos, é possível que as temperaturas atingidas pela amostra durante a secagem via radiação IV tenham favorecido a ocorrência de reações de Maillard.

Equações cinéticas de ordem zero e de primeira ordem foram ajustadas aos dados experimentais. Para a condição de $100 \mathrm{~W} / \mathrm{m}^{2}$, a cinética de escurecimento foi melhor descrita por uma equação de ordem zero, enquanto para as outras condições a equação de $1^{a}$ ordem apresentou melhor capacidade de predição, com base no índice de correlação em cada caso.

Os resultados obtidos são apresentados na Tabela 2. 
Tabela 2 - Resultados da análise de regressão não-linear da cinética de escurecimento do pólen apícola aplicando modelos de ordem zero e de primeira ordem.

\begin{tabular}{c|c|c|c|c|c|c|c}
\hline \multirow{2}{*}{$\mathrm{IR}\left(\mathrm{W} / \mathrm{m}^{2}\right)$} & \multirow{2}{*}{$t(\min )$} & \multirow{2}{*}{$T_{s}\left({ }^{\circ} \mathrm{C}\right)$} & \multicolumn{3}{|c|}{ Ordem zero } & \multicolumn{2}{c}{ Primeira ordem } \\
\cline { 4 - 8 } & & & $\mathrm{C}_{\mathrm{o}}$ & $\alpha_{0}\left(\mathrm{~min}^{-1}\right)$ & $\mathrm{R}^{2}$ & $\alpha_{1}\left(\mathrm{~min}^{-1}\right)$ & $\mathrm{R}^{2}$ \\
\hline 100 & 93 & 77,1 & 60,9 & 0,31 & 0,9550 & $2,0 \cdot 10^{-3}$ & 0,3244 \\
\hline 400 & 76 & 127,9 & 51,5 & 3,54 & 0,9223 & $3,1 \cdot 10^{-2}$ & 0,9449 \\
\hline 700 & 16 & 153,0 & 87,7 & 6,41 & 0,9361 & $5,3 \cdot 10^{-2}$ & 0,9542 \\
\hline
\end{tabular}

Após o ajuste da Equação 11 aos dados experimentais, obtiveram-se o parâmetro préexponencial $\alpha=1,29 \cdot 105\left(\mathrm{~min}^{-1}\right)$ e a energia de ativação $E_{a}=52,19 \mathrm{~kJ} \mathrm{~mol}^{-1} \mathrm{com}$ um valor de $R^{2}=0,9991$. Os valores determinados pertencem à mesma faixa encontrada por Maskan (2001) e evidenciam que a intensidade de radiação aumenta a taxa de escurecimento.

O ângulo hue $\left(H^{*}\right)$ indica a tonalidade. Inicialmente os grãos de pólen apresentam um valor de $H^{*}$ igual 79,0 $\pm 0,5$; este valor, entre 70 e $80^{\circ}$, indica a cor alaranjada dos grãos. Conforme apresentado na Figura 8, houve uma redução acentuada do valor de $H^{*}$ indicando a mudança da tonalidade da cor dos grãos no sentido de intensificação da tonalidade vermelha.

Figura 8 - Ângulo hue dos grãos de pólen apícola ao longo do processo de secagem IV em camada fina, parametrizado nas diferentes intensidades de radiação empregadas.

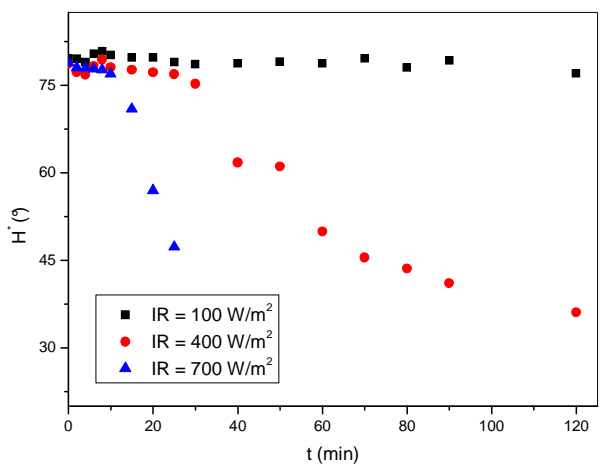

A coordenada croma, ou índice de saturação mensura a intensidade da cor. As curvas da evolução da coordenada croma durante o processo de secagem IV dos grãos de pólen são apresentadas na Figura 9. Verificou-se que, inicialmente os grãos de pólen apresentam um valor de $C^{*}$ igual $28,9 \pm$ 0,3 .

Figura 9 - Índice de saturação dos grãos de pólen apícola ao longo do processo de secagem infravermelho em camada fina, parametrizado nas diferentes intensidades de radiação empregadas.

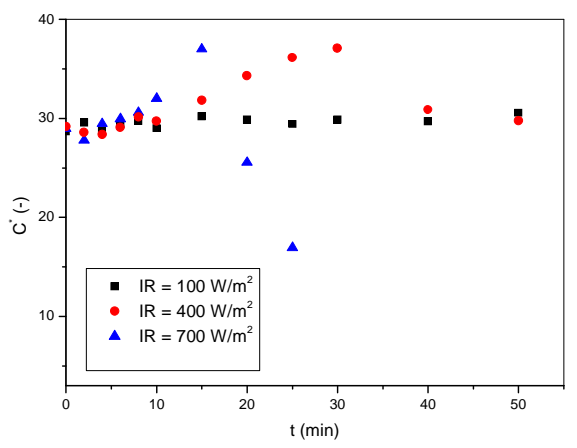

Houve um aumento da intensidade da cor seguido de uma redução brusca do valor de $C^{*}$ para as condições mais intensas de fluxo de radiação $\left(400\right.$ e $\left.700 \mathrm{~W} / \mathrm{m}^{2}\right)$. Este fato evidencia o escurecimento do material como foi relatado anteriormente em relação ao índice de escurecimento (Figura 7). Para a condição de intensidade de radiação de 100 $\mathrm{W} / \mathrm{m}^{2}$, o índice de saturação permanece praticamente inalterado ao longo de todo o processo e igual a $31,3 \pm 2,6$.

\section{CONCLUSÕES}

$\mathrm{O}$ aumento da intensidade de radiação provocou, como esperado, uma maior remoção de umidade, num menor tempo de processo. O tempo de secagem para reduzir o teor de umidade dos grãos para o valor alvo 
de $4 \%$ b.u., recomendado pela legislação brasileira, foi de $(60 \pm 5) \min ,(18 \pm 2)$ min e $(9 \pm 1)$ min, para as intensidades de radiação IV de 100,400 e $700 \mathrm{~W} / \mathrm{m}^{2}$, respectivamente.

Durante o processo de secagem, verificou-se a perda de brilho e o aumento da coordenada $a^{*}$ nos grãos de pólen. O escurecimento dos grãos foi intensificado pelo aumento da intensidade de radiação, indicando que as altas temperaturas atingidas pela amostra durante a secagem via radiação IV podem ter favorecido a ocorrência de reações de Maillard, visto que o pólen apícola é rico em açúcares e aminoácidos.

Para a condição de $100 \mathrm{~W} / \mathrm{m}^{2}$, a cinética de escurecimento foi melhor descrita por uma equação de ordem zero, enquanto para as outras condições a equação de $1^{\text {a }}$ ordem apresentou melhor capacidade de predição.

Apesar de acelerarem o processo de secagem, elevados fluxos de energia radiante intensificam a degradação de cor do material. Isto porque as taxas de reações de escurecimento tendem a aumentar com o aumento da temperatura do produto, o que ocorre em maior magnitude durante a secagem a 400 e $700 \mathrm{~W} / \mathrm{m}^{2}$.

Dentre as condições operacionais investigadas, apenas a secagem IV a 100 $\mathrm{W} / \mathrm{m}^{2}$ é recomendada para assegurar a preservação dos atributos de cor do pólen apícola.

\section{NOMENCLATURA}

Coordenada do sistema

$a^{*} \quad$ Hunter que indica a faixa de cor do verde ao vermelho e

Coordenada do sistema

$b^{*} \quad$ Hunter que indica a cor do material do azul ao amarelo

$C^{*} \quad$ Coordenada croma

$D_{\text {eff }} \quad$ Difusidade efetiva

IE Índice de escurecimento

Coordenada do sistema

$L^{*} \quad$ Hunter que indica a luminosidade do material

$$
\begin{array}{cc}
t & \text { Tempo } \\
T & \text { Temperatura } \\
X & \text { Umidade do sólido, massa de } \\
X_{e} & \text { água por massa de sólido seco } \\
& \text { Umidade de equilíbrio } \\
X R & =\frac{X-X_{e}}{X_{o}-X_{e}}, \text { Umidade } \\
& \text { adimensional }
\end{array}
$$

\section{AGRADECIMENTOS}

Os autores agradecem ao $\mathrm{CNPq}$ pelo auxílio financeiro.

\section{REFERÊNCIAS}

ACEVEDO, N.; SCHEBOR,C.; BUERA,M.P.. Water-solids interactions, matrix structural properties and the rate of non-enzymatic browning. Journal of Food Engineering. v. 77(4). 2006. p. 1108-1115.

ARGYROPOULOS, D.; MÜLLER, J.. Kinetics of change in colour and rosmarinic acid equivalents during convective drying of lemon balm (Melissa officinalis L.), Journal of Applied Research on Medicinal and Aromatic Plants. v. 1. 2014. p. e15-e22.

BARBOSA NETO, A. M. ; MARQUES, L. G. ; PRADO, M. M. ; SARTORI, D. J. M. . Mass Transfer in Infrared Drying of GelCoated Seeds. Advances in Chemical Engineering and Science, v. 04, p. 39-48, 2014.

BRASIL, 2001. Instrução Normativa n. 3 de 2001. Regulamentos Técnicos de Identidade e Qualidade, de Apitoxina, de Cera de Abelha, de Geléia Real, de Geléia Real Liofilizada, de Pólen Apícola, de Própolis, de Extrato de Própolis) FERREIRA, R. C. Avaliação das características fisico-químicas e microbiológica do pólen da Melipona scutellaris Latreille submetido a diferentes 
processos de desidratação. Dissertação (Mestrado em Ciência de Alimentos), Universidade Federal da Bahia, UFBA. 2012.

JUN, S.; KRISHNAMURTHY, K.; IRUDAYARAJ, J. DEMIRCI, A.. Fundamentals and Theory of Infrared Radiation. In: ATUNGULU, G. G.; PAN, Z.. Infrared Heating for Food and Agricultural Processing. Chapter 1. (Contemporary Food Engineering). 2010. 300 p.

KATIFORI, E.; ALBEN, S.; CERDA, E.; NELSON, D. R.; DUMAIS, J.. Foldable structures and the natural design of pollen grains. Proceedings of the National Academy of Sciences of the United States of America. v.107(17). 2010. p.7635-9.

LAVERDE, L. M.; ACEVEDO, A. N. C.; SCHEBOR, C.; BUERA, M. D. P.. Integrated approach for interpreting browning rate dependence with relative humidity in dehydrated fruits. LWT - Food Science and Technology. v 44(4). 2011. p. 963-968

MANZOCCO, L.; CALLIGARIS， S.; MASTROCOLA, D.; NICOLI, M. C.; LERICI, C. R.. Review of non-enzymatic browning and antioxidant capacity in processed foods. Trends in Food Science \& Technology. v. 11 (9-10). 2000. p. 340-346.

MASKAN, M.. Kinetics of colour change of kiwifruits during hot air and microwave drying. Journal of Food Engineering. v. 48(2). 2001. p. 169-175.

MATSUDA, H.; LLAVE, Y.; FUKUOKA, M.; SAKAI, N.. Color changes in fish during grilling - Influences of heat transfer and heating medium on browning color. Journal of Food Engineering. v. 116(1). 2013. p. 130-137.

PALOU, E.; LÓPEZ-MALO, A.; BARBOSA-CÁNOVAS,G.V.; WELTICHANES, J.; SWANSON, B.G.
Polyphenoloxidase activity and color of blanched and high hydrostatic pressure treated banana puree. Journal of Food Science. v. 64. 1999. p. 42-45.

PASCOAL, A.; RODRIGUES, S.; TEIXEIRA, A.; FEÁS, X.; ESTEVINHO, L. M.. Biological activities of commercial bee pollens: Antimicrobial, antimutagenic, antioxidant and anti-inflammatory. Food and Chemical Toxicology. v. 63. 2014. p. 233239.

PAWAR, S., KUMAR, P., MUJUMDAR, A. S.; THORAT, B. Infrared Convective Drying of Organic Pigments. Drying Technology, 26: p. 315-322. 2008.

PONKHAM, K.; MEESO, N.; SOPONRONNARIT, S.; SIRIAMORNPUN, S.. Modeling of combined far-infrared radiation and air drying of a ring shapedpineapple with/without shrinkage. Food and Bioproducts Processing. v.90. ed 2. 2012. p.155-164

ROCHA, J. F. M. Avaliação do efeito do armazenamento na qualidade do pólen apícola. Dissertação (Mestrado em Qualidade e Segurança Alimentar). Escola Superior Agrária de Bragança. Bragança, 2013.

SANDU, C.. Infrared Radiative Drying In Food Engineering: a process analysis. Biotechnology Progress. v 2(3). 1986. p. 109-119.

SANTOS, L. D. M. ; PRADO, M. M. . Estudo da Secagem de Moringa oleifera. In: XVIII Congresso Brasileiro de Engenharia Química, 2010, Foz do Iguaçu. Anais do XVIII COBEQ, 2010. v. 1.

WU, B.; PAN, Z.; QU,W.; WANG, B.; WANG, J.; MA, H. Effect of simultaneous infrared dry-blanching and dehydration on quality characteristics of carrot slices. LWT Food Science and Technology. v. 57. 2014. p. 90-98. 